\title{
Effect of $\mathrm{Gr}$ Contents on Wear Properties of Al2024/MgO/Al2O3/Gr Hybrid Composites
}

\author{
İsmail Ovalı 1,a , Cemal Esen ${ }^{2}$, Sevda Albayrak ${ }^{3}$ and Halil Karakoç ${ }^{4}$ \\ ${ }^{1}$ Pamukkale University, Department of Manufacturing Engineering, 20160 Denizli, Turkey \\ ${ }^{2}$ Celal Bayar University, Department of Mechanical and Manufacturing Engineering,Manisa, Turkey \\ ${ }^{3}$ Gazi University, Department of Metallurgy and Materials Eng., 06500 Ankara, Turkey \\ ${ }^{4}$ Hacettepe University, Department of Mechanical Program, 06935 Ankara, Turkey
}

\begin{abstract}
In the present study, hybrid metal matrix composites, Al2024/10Al2O3, $\mathrm{Al} 2024 / 10 \mathrm{Al} 2 \mathrm{O} 3 / 3 \mathrm{MgO}, \quad \mathrm{Al} 2024 / 10 \mathrm{Al} 2 \mathrm{O} 3 / 6 \mathrm{MgO}, \quad \mathrm{Al} 2024 / 10 \mathrm{Al} 2 \mathrm{O} 3 / 3 \mathrm{MgO} / 1.5 \quad \mathrm{Gr}$, A12024/10A12O3/3MgO/3Gr, and reinforcement samples (AA 2024) produced with powder metallurgy process. AA 2024 and reinforcement powders were determined mixture rations and separately mixed during 30 minutes in a three-dimensional Turbula mixer. The mixed compositions were pressed at $300 \mathrm{MPa}$ and sintered at $550^{\circ} \mathrm{C}$ during $1 \mathrm{~h}$. After that, three materials were extruded at the same temperature. Experimental results show that hybrid metal matrix composites (HMMCs) a better wear resistance than the reinforcement samples because of higher hardness. Gr behave as a lubricant during wear process. The wear resistance of HMMCs can be optimized with controlling of the reinforcement content and type.
\end{abstract}

\section{Introduction}

Metal matrix composites (MMCs) reinforced with harder particles have been extensively used in automotive and aerospace industries because of their superior mechanical properties. Gr also are used in the MMCs as lubricator [1-3].Adding of Gr significiantly improve wear performance of MMCs.

Şahin et al devoloped the regression models. The model show that with increasing load increrase the wear rate. However, it decreases with increasing of sliding distance [4]. In a study by Al-Rubaie, increasing in reinforcement size of Al-SiC composites improved wear resistance [4]. Basavaraja et al. (2006) investigated the dry friction wear behavior of hybrid composites. They reported that the wear resistance increased with the increase of $\mathrm{SiCp}$ and graphite \% wt and the wear rate decreased with increasing $\mathrm{SiC} \%$ wt [5]. Alahelisten et al. studied that, the tribological performance of a composite depends on the microstructure properties of the material and the wear conditions [6]. Basavarajapa et al. fond that using of graphite particles in aluminum matrix improve wear resistance and form a lubricant layer between the friction surfaces [7].

Topcu et al. studied the mechanical properties of $\mathrm{B} 4 \mathrm{C}$ reinforced $\mathrm{Al}$ composites the composite hardness increased with increasing of reinforcement \% wt. [8]. Deuis et al. reported the effect of particle size and \%wt. on the wear behavior of aluminum matrix composites and found that the most important parameters are sliding distance and load [7]. Suresha and Shridhara revealed that adding hard particle such as $\mathrm{SiC}$ and $\mathrm{Gr}$ improve the wear resistance of hybrid composites [7]. The effect of

${ }^{\text {a }}$ Corresponding author : iovali@pau.edu.tr 
$\mathrm{B} 4 \mathrm{C}$ on the wear performance and mechanical properties of $\mathrm{Al}$ 7075-B4C composites were investigated by Baradeswaran and Elaya Perumal. They observed that increasing B4C particles increase the wear performance of the composites when compared to the matrix alloy [9].

In the present work, the effects of reinforcement type and \% wt. content, (Al6061), (\%12B4C), $(\% 12 \mathrm{SiC}), \quad(\% 9 \mathrm{~B} 4 \mathrm{C}+\% 3 \mathrm{SiC}), \quad(\% 6 \mathrm{~B} 4 \mathrm{C}+\% 6 \mathrm{SiC})$ ve $(\% 3 \mathrm{~B} 4 \mathrm{C}+\% 9 \mathrm{SiC})$, on the abrasive wear performance of $\mathrm{A} 12024$ hybrid matrix composites produced with hot pressing methods were investigated.

\section{Experimental}

\subsection{Material and methods}

The 6061 series aluminium matrix material powder size was taken less than $100 \mu \mathrm{m}$. The chemical composition of AA 2024 has shown in the Table 1. The powder properties also is given in Table 2. First of all, AA 2024 and reinforcement powders were determined mixture rations and separately mixed during 30 minutes in a three-dimensional Turbula mixer. After that, AA 2024 and hybrid composites were prepared in the same parameters. All of volume fractions were shown in Table 3. During experimental work, the reinforcement was added slowly for homogeneous distribution. The mixed compositions were pressed at $300 \mathrm{MPa}$ and sintered at $550^{\circ} \mathrm{C}$ during $1 \mathrm{~h}$. After that, three materials were extruded at the same temperature. It was used a pre-heated hydraulic extrusion mold and consist of shaped metal blocks. Flow diagram of process is shown in Fig. 1.

Table 1. The chemical composition of Al2024 alloy.

\begin{tabular}{|l|c|c|c|}
\hline \multicolumn{1}{|c|}{ Component } & Wt. $\%$ & Component & Wt. \% \\
\hline Aluminum (Al) & 90.7 to 94.7 & Zinc $(\mathrm{Zn})$ & 0 to 0.25 \\
\hline Copper $(\mathrm{Cu})$ & 3.8 to 4.9 & Zirconium $(\mathrm{Zr})$ & 0 to 0.2 \\
\hline Magnesium $(\mathrm{Mg})$ & 1.2 to 1.8 & Titanium (Ti) & 0 to 0.15 \\
\hline Manganese $(\mathrm{Mn})$ & 0.3 to 0.9 & Chromium $(\mathrm{Cr})$ & 0 to 0.1 \\
\hline Iron $(\mathrm{Fe})$ & 0 to 0.5 & Residuals & 0 to 0.15 \\
\hline Silicon $(\mathrm{Si})$ & 0 to 0.5 & & \\
\hline
\end{tabular}

Table 2. Properties of matrix and reinforcing powders

\begin{tabular}{|l|c|c|c|c|}
\hline \multicolumn{1}{|c|}{ Material } & $\begin{array}{c}\text { Manufacturing } \\
\text { Process }\end{array}$ & Density (g/cm3 ) & $\begin{array}{c}\text { Melting } \\
\left.\text { Temperature ( }{ }^{\circ} \mathbf{C}\right)\end{array}$ & Grain size \\
\hline $\mathbf{A l 2 0 2 4}$ & Gas atomization & 2.78 & $502-638$ & $<100 \mu \mathrm{m}$ \\
\hline $\mathbf{A l}_{\mathbf{2}} \mathbf{O}_{3}$ & --- & 3,97 & 2040 & $<8 \mu \mathrm{m}$ \\
\hline $\mathbf{M g O}$ & --- & 3.58 & 2852 & $10-30 \mathrm{~nm}$ \\
\hline $\mathbf{G r}$ & --- & & & $<10 \mu \mathrm{m}$ \\
\hline
\end{tabular}


Table 3. Hiybrid Composite materials

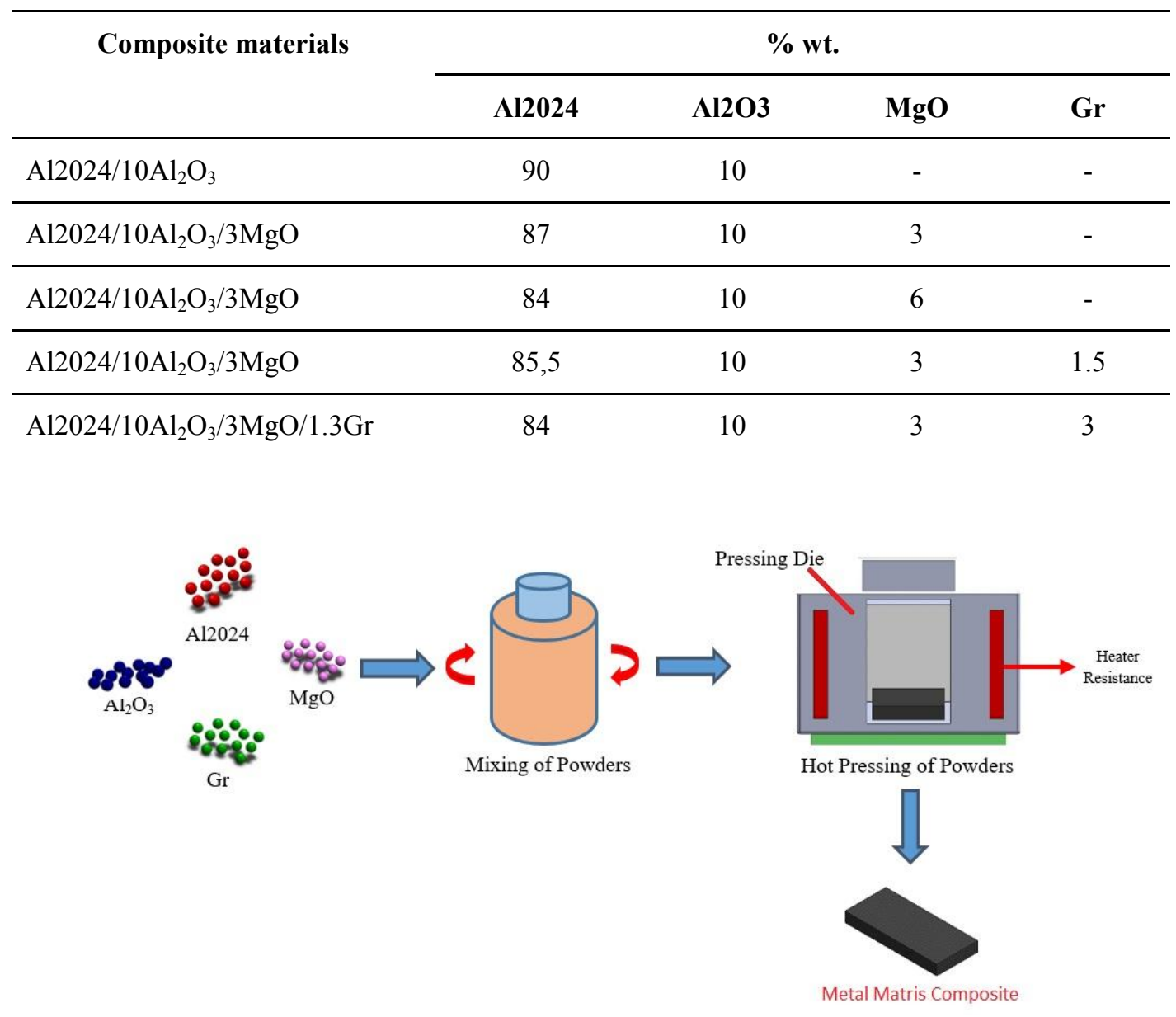

Figure 1. Schematic representation of AMC composite fabrication by hot pressing.

The wear test were carried out by a pin-on-disk wear-testing devices according to ASTM G132-96 (Figure 2). The wear tests were carried out by a pin-on-disk wear-testing device according to ASTM G132-96. Samples surfaces were grounded with $80 \mathrm{SiC}$ paper for removing rough surface than the ACM test pin, with a diameter of $10 \mathrm{~mm}$, was fixed and counterface abrasive disk (abrasive paper 150 grit) during the test.The wear test was performed in distance 100, 200 and $300 \mathrm{~m}$, at speed of $1.2 \mathrm{~m} / \mathrm{s}$ and with imposed load of 5, 10 and $15 \mathrm{~N}$. Prior to measuring, samples were cleaned in acetone for cleaning of surface contaminants, dried and then weighed using an electronic balance having a resolution of $0.001 \mathrm{mg}$. 


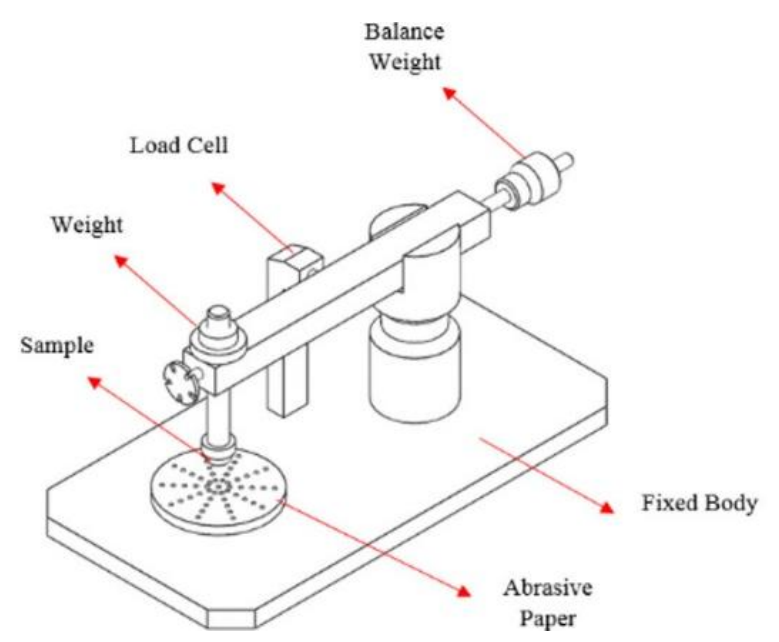

Figure 2. Pin-on-disk wear-testing set-up

\section{Result and Discussion}

\subsection{Effect of the sliding distance and load on the weight loss of HMMCs}

The variation in weight loss of HMMCs and unreinforced composite Al 2024 as a function of load are shown in Figure 3. 


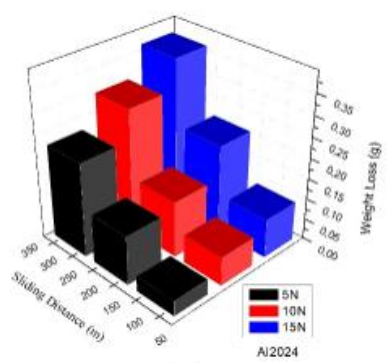

a

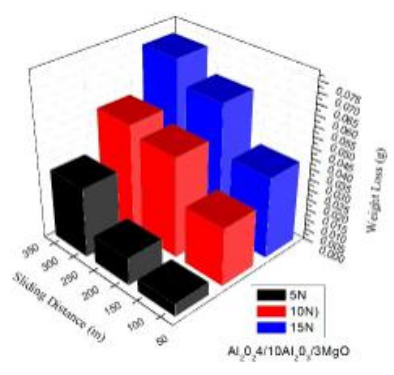

$\mathrm{c}$

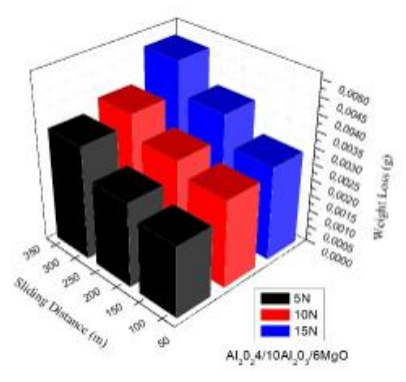

$\mathrm{c}$

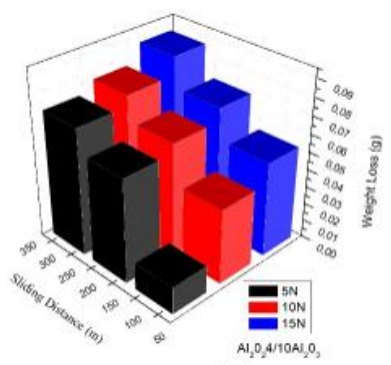

b

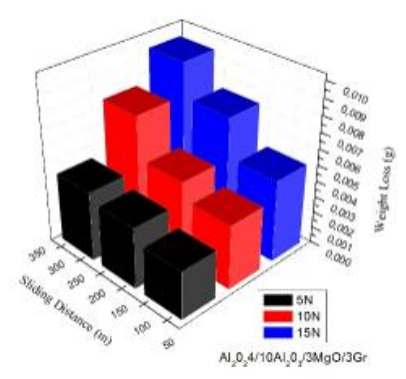

d

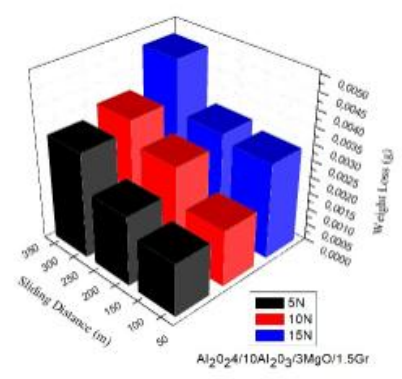

$\mathrm{f}$

Figure 3. Variation in weight loss as a function of sliding distance and load a) A12024 b)Al2O24/10A12O3 c) $\mathrm{Al} 2 \mathrm{O} 24 / 10 \mathrm{~A} 12 \mathrm{O} 3 / 3 \mathrm{MgO}$ d)Al2O24/10A12O3/3MgO/3Gr $\mathrm{A} 12 \mathrm{O} 24 / 10 \mathrm{~A} 12 \mathrm{O} 3 / 3 \mathrm{MgO} / 1.5 \mathrm{Gr}$

e) $\mathrm{A} 12 \mathrm{O} 24 / 10 \mathrm{~A} 12 \mathrm{O} 3 / 6 \mathrm{MgO}$ )

As can be seen form Figure 3 that weight loss increase with increasing load and sliding distance. The result can be related to high temperature forming at contact face. Similar results were obtained by previous studies [10-12]. Al reinforcement particles ( $\mathrm{Al} 2 \mathrm{O} 3, \mathrm{MgO}, \mathrm{Gr})$ have the positive effect on the wear resistance. The highest wear resistance was obtained at Al 2024/10Al2O3/3MgO/1.5Gr hybrid composite samples (Figure 3a). It can be concluded that adding $\mathrm{Gr}$ increase hardness and wear resistance when compared weight loss of Al $2024 / 10 \mathrm{Al} 2 \mathrm{O} / 3 / 3 \mathrm{MgO}$ and $\mathrm{Al}$ $2024 / 10 \mathrm{Al} 2 \mathrm{O} / 3 / 3 \mathrm{MgO} / 3 \mathrm{Gr}$. It is well known that $\mathrm{Gr}$ also have lubricant effects. The effects also increase the wear performance of metal matrix composite. Graphite layer are formed by adding Gr. Riahi and Alpas [13] find that wear resistance of composites reinforced with graphite are higher when compared with unreinforced A356 and nongraphitic A356/20SiCp samples. The similar higher wear 
resistance results were obtained at previous studies which used ceramics and graphite as reinforcement [14-15].

\subsection{Effect of the reinforcement type and \%wt. on Hardness of HMMCs}

The hardness property is widely used in order to evaluate the effects of reinforcement type and \%wt. on the wear resistance. The hardness of the unreinforced and HMMCs samples are given in the Figure 4.

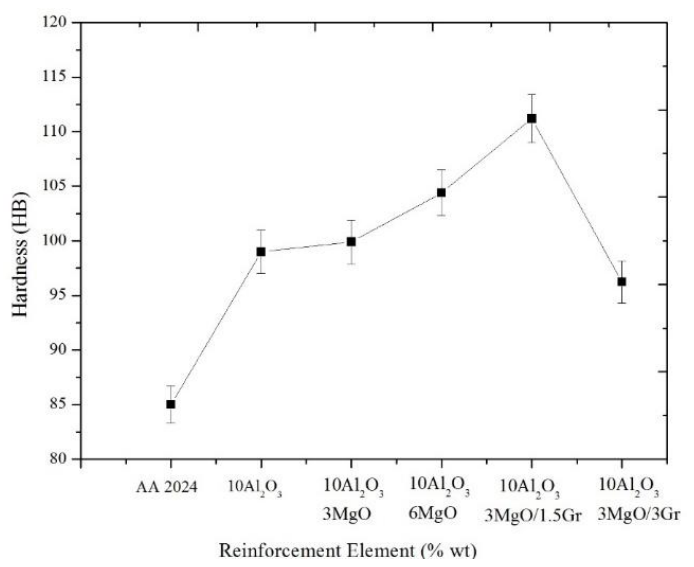

Figure 4. The hardness of the HMMCs samples

The lowest hardness was obtained for Un-reinforcement Al2024 samples at $85 \mathrm{HB}$ while the highest hardness was obtained for $\mathrm{Al} 2024 / 10 \mathrm{Al} 2 \mathrm{O} 3 / 3 \mathrm{MgO} / 1.5 \mathrm{Gr}$ at $111.2 \mathrm{HB}$. It can be explained that harder reinforcement particles increased to compression and tensile strength of the matrix material [16]. Some previous studies show similar results for effects reinforcement on the hardness [13-15].

\section{REFRENCES}

1. A.R. Riahi and A.T. Alpas, Wear, 251 p 1396-1407 (2001)

2. S. Mohan, J.P. Pathak, R.C. Gupta, and S. Srivastava, Z. Metallkd, 93(12) p 1245-1251 (2002)

3. S. Das, S.V. Prasad, and T.R. Ramachandran, Wear, 133 p 173-187 1(989)

4. N. Ch. Kaushik, R. N. Rao, Trib. Inter.1, 103 298-308 (2016)

5. V. M. Ravindranath, M.Yerriswamy, S. V. Vivek, G. S Shiva Shankar, N. G Siddesh Kumar, Mat. Tod.: Proc., 4 9898-9901(2017)

6. M. Uthayakumar, S. Aravindan, K. Rajkumar, Mat.and Des., 47 456-464 (2013)

7. T. Lokesh, U. S. Mallik, Mat. Tod.: Proc.s, 4 11175-11180 (2017)

8. Y. H. Çelik, K. Seçilmiş, Adv. Pow.Tech., 28 2218-2224 (2017)

9. S. Thirumalai Kumaran, M. Uthayakumar, Pro. of the Ins. of Mech. Eng., Part J: J. of Eng. Trib. 2014 228: 332 originally published online 18 October 2013 DOI: 10.1177/1350650113508103

10. R.L. Deuis, C. Subramanian, and J.M. Yellup, Wear, 201 p 132-144 (1996)

11. J. Goni, Mater. Sci. Technol., 16 p 743-746 (2000)

12. G.J. Howell and A. Ball, Wear, 181- 183 p 379-390 (1995)

13. A.R. Riahi and A.T. Alpas, Wear, 251 p 1396-1407 (2001)

14. S.K. Rhee, SAE Trans., paper 740415, (1974)

15. P.K. Rohatgi, S. Ray, and Y. Liu, Int. Mat. Rev., 37 p 129- 149 (1992)

16. B. Venkataraman and G. Sundararajan, Wear, 245 p 22-38 (2000) 